\title{
Dilemma in the Development of Modern Timber Architecture and Its Countermeasures
}

\author{
Liang Pan* \\ Lishui Vocational and Technical College, Lishui 323000, Zhejiang Province, China \\ *Corresponding author: Liang Pan, p108041615@sina.cn
}

Copyright: ( $) 2022$ Author(s). This is an open-access article distributed under the terms of the Creative Commons Attribution License (CC BY 4.0), permitting distribution and reproduction in any medium, provided the original work is cited.

\begin{abstract}
Under the context that "peak carbon emissions" and "carbon neutrality" are included in the overall plan for the construction of ecological civilization in China, this paper discusses the value of modern timber architecture as a form of lowcarbon and environmental protection movement in the whole life cycle of the construction field. It mainly analyzes the reasons for the limited resources, misunderstandings of inherent concepts, the high cost of comprehensive construction, and the shortage of professionals. Based on that, several countermeasures have been proposed, such as perfecting relevant norms and policies, strengthening technology research and development as well as demonstration guidance, moderately developing forest resources, applying digital construction operation and maintenance technology, as well as cultivating compound professionals, all of which provide a reference for the development of ecological benefits in China's construction industry.
\end{abstract}

Keywords: Beautification; Modern timber architecture; Ecological benefits; Dilemma; Countermeasures

Online publication: January 12, 2022

\section{Introduction}

The terms "peak carbon emissions" and "carbon neutrality" appeared for the first time in the government work report of the National People's Congress in 2021, with a commitment to hit peak carbon emissions before 2030 and attain carbon neutrality before $2060^{[1]}$. In the midst of implementing energy conservation and emission reduction in the construction industry, the Ministry of Housing and Urban-Rural Development issued the Calculation Standard for Architecture's Carbon Emissions, which clearly defined the carbon emissions of buildings, calculation boundaries, carbon emission factors, the carbon sinks of buildings, global warming potential, etc., among which the carbon emissions of buildings include the sum of greenhouse gas emissions generated by buildings during production and transportation, construction and demolition, as well as the operational stages of related building materials ${ }^{[2]}$. With the enforcement of the concept of green ecology in the construction industry and the proposal of the concepts of ecological city and landscape garden city, modern timber structure architecture with green environmental protection, comfort, and livability as the starting point would bring great ecological and economic benefits. Modern timber architecture refers to the construction in which the main structural components are made of standardized synthetic timber or engineering timber products, and the connecting nodes of components are connected by metal connectors. Amidst the implementation of "carbon neutrality" and green development in the construction industry, modern timber architecture has important practical significance for sustainable green development in the construction field. 


\section{Application value of modern timber architecture}

\subsection{Promoting the transformation and upgrading of the construction industry}

The construction industry has always been a large energy consumption industry. According to the Chinese Buildings' Energy Consumption Research Report 2020 issued by China Association of Building Energy Efficiency, the total energy consumption in the whole process of construction in China in 2018 was 21.47 tce, accounting for $46.5 \%$ of China's total energy consumption; the total carbon emissions were 49.3-ton $\mathrm{CO}_{2}$, accounting for $51.3 \%$ of China's carbon emissions ${ }^{[3]}$. Among many building materials, timber, boasting as the only natural renewable material, also known as "negative carbon" material, has certain characteristics, which include carbon fixation and energy conservation. Timber architectures have the advantage of storing carbon dioxide in nature. Research has shown that $100 \mathrm{~m}^{2}$ of these architectures can store about 10 tons to 30 tons of carbon dioxide ${ }^{[4]}$. In addition, from the perspective of the mechanical properties of materials, the strength-to-weight ratio of timber is much better than that of steel and concrete, indicating that compared with the other two materials, timber can meet the strength requirements with a smaller cross-sectional area and greatly reduce the dead weight of the structure. In light of the structure of buildings, compared with steel and concrete structures, the energy consumption of timber in the process of material production and processing as well as the carbon emissions after production are lower. Research has shown that carbon emissions in the production stage can be reduced by 48.9\% 94.7\%; from the analysis of carbon emissions in the whole life cycle of buildings, 8.6\% 13.7\% of carbon dioxide emissions can be saved ${ }^{[5]}$, which embodies excellent environmental protection advantages and is conducive to reducing carbon emissions in the construction industry. Table 1 shows the impact of the life cycle of main building materials on the environment ${ }^{[6]}$.

In recent years, prefabricated buildings have been widely used in the construction industry because of their advantages, which include industrialization, standardization, high efficiency, and green construction. Timber serves as a natural prefabricated architectural form, and thus the implementation of prefabricated timber architecture is of practical significance to the industrialization of the construction industry. Prefabricated timber architecture is prefabricated in factories and then transported to the site for assembly [6], which saves on on-site labor costs and resources, is convenient for construction, is conducive to improving the industrialization level of the construction industry, as well as effectively promotes the transformation and upgrading of the construction industry.

Table 1. Impact of the life cycle of main building materials on the environment

\begin{tabular}{cccccc}
\hline Category & Water pollution & Greenhouse effect & Air pollution index energy & Solid waste & Energy consumption \\
\hline Timber & 1 & 1 & 1 & 1 & 1 \\
Cement & 120 & 1.47 & 1.44 & 1.37 & 1.9 \\
Steel & 0.9 & 1.88 & 1.69 & 1.95 & 1.5 \\
\hline
\end{tabular}

\subsection{Improving the green business and living environment}

Modern timber architecture has flexible structural style, and its design conforms to the original demand for space, which creates more possibilities for the function of space without destroying harmony, but rather boasting the "walking" architecture. The low-carbon attribute of timber architecture can also be effectively combined with the green business in this region, which is in line with the current concept of green economic development and promotes the cultivation of new economic business. With the development of social economy, more and more high-rise buildings with steel and concrete structures are merging in cities. People get in touch with nature and relax through tourism. This has given birth to the vigorous development of 
new business services, such as cultural tourism and forest health care. The ecological label of timber architecture has made it more preferable in the construction of tourist areas, forest areas, and rural towns. These timber architectures are integrated with cultural tourism at scenic spots and characteristic towns to create original ecological buildings. In forest areas, living in harmony with the forest is a style that would not destroy or affect the existing forest landscape, but rather it highlights the natural beauty of timber structures along with the poetic and picturesque scenery among mountains, rivers, and vegetation. The setting of the timber house as the form, the flowers and grass as mediums, and human care as the principle form new artistic and cultural artistic conception. Along this line, timber architecture with strong local flavor will become a new form and choice of rural tourism, which would assist rural revitalization ${ }^{[7-9]}$. On the other hand, modern timber architecture with beautiful, practical, and rich cultural characteristics can be applied to urban ecological landscapes, forming a harmonious unity between the natural environment and the living environment, thus meeting the requirements of national forest city construction ${ }^{[10]}$.

\subsection{Enhancing the overall performance of buildings}

Earthquakes pose huge damages to the production and life of society, such as social disorders and major losses in terms of personnel and properties. Therefore, earthquake resistance has always been a key research topic in the field of civil and architectural engineering. Engineering experiments have shown that the heavier the dead weight of a building in the event of earthquakes, the more severe the shaking intensity will be. Compared with steel and concrete materials, timber has a lighter dead weight. Research has shown that the dead weight of reinforced concrete buildings is about 5 times that of timber structures under the same volume. Besides, the deformation property of timber can be utilized, as timber has high toughness and elasticity, is capable of absorbing part of the energy generated by earthquakes, and has strong resistance to instantaneous impact load as well as periodic fatigue damage, indicating that the whole building would shake more without collapsing during an earthquake ${ }^{[11]}$. In view of the good seismic performance of timber, most architectures in Japan are mainly timber structures. Modern timber structures have been used for several reconstruction projects after Wenchuan earthquake in China as exemplified by Xiang'e Primary School in the suburb of Dujiangyan, where its buildings are now made from timber structures.

Thermal insulation is an important part of building energy conservation. Timber is a natural thermal insulation material. Research has shown that the thermal insulation performance of timber is 400 times that of steel and 16 times that of concrete. The thermal insulation performance of a timber wall with thickness of $150 \mathrm{~mm}$ is equivalent to that of a $610 \mathrm{~mm}$ brick wall. Under the same building area, timber architectures can save more than $40 \%$ of energy compared with brick-concrete buildings ${ }^{[12]}$.

\section{Problems existing in the popularization of modern timber architecture}

\subsection{Limited resources}

Timber architecture occupies an important position in the architectural history of China. Traditional timber architecture came about during the Qin and Han Dynasties, flourished during the Tang and Song Dynasties, and reached its peak during the Ming and Qing Dynasties. Due to frequent social wars, social system changes, and the reduction of timber volume in modern China, timber architecture has declined. In the 1970s, in consideration of the shortage of forest resources in China, the policy of replacing timber with steel and plastic was put forward. In the 1980s, the utilization of timber structures for housing construction was stopped as domestic forest resources were almost exhausted ${ }^{[13,14]}$. Since then, reinforced concrete buildings and reinforced structure buildings, which are more suitable for social and economic development, have become common building structures. At the same time, with the slow development of timber architecture, the research progress of new technologies related to timber architecture is delayed, and the 
corresponding technical specifications and standards are not comprehensive enough, thus limiting the applicability of the whole modern timber architecture.

\subsection{Misunderstandings of inherent concepts}

Due to the low proportion of timber architectures in China over the past 30 years, most of the timber architectures that can be seen are timber dwellings in villages, which leads to prejudice and misunderstandings toward timber architecture. Most people think that timber architecture is still the same as ancient timber architecture, and they mistakenly equate timber structures with traditional timber structures, with little understanding about the concept of modern timber structures. Wang Ruisheng and Chen Youliang compared modern timber architecture with traditional timber architecture, as shown in Table $2^{[15]}$. It can be concluded that modern timber architecture is different from traditional timber architecture in terms of raw materials, processing methods, and construction methods, of which modern timber architecture can better adapt to the needs of contemporary social development and reflect the development level of today's social productive forces.

Table2. Comparison between traditional timber architecture and modern timber architecture

\begin{tabular}{|c|c|c|}
\hline Category & Traditional timber architecture & Modern timber architecture \\
\hline Building materials & Natural timber & Engineering timber, artificial timber \\
\hline Processing method & Natural air drying & Modern advanced industrial technology treatment \\
\hline Structure type & $\begin{array}{c}\text { Beam lifting type, bucket piercing type, dense } \\
\text { beam flat top type }\end{array}$ & $\begin{array}{c}\text { Ordinary timber structure, glued timber structure, } \\
\text { light timber structure }\end{array}$ \\
\hline Connection mode & $\begin{array}{l}\text { Mortise-tenon connection, bucket-arch } \\
\text { connection }\end{array}$ & $\begin{array}{l}\text { Notch and tooth connection, bolt connection and } \\
\text { nail connection, tooth-plate connection }\end{array}$ \\
\hline Number of cycles & Disposable & $6 \sim 7$ times \\
\hline Industrial paradigm & Relies on resources and production factors & Relies on innovation and technological progress \\
\hline
\end{tabular}

Another inherent concept of timber is that timber is a combustible material, and timber-constructed houses are prone to fire. Many magnificent ancient timber buildings in history were destroyed by fire; in addition, the safety of houses built with timber cannot be guaranteed. Moreover, the low durability of timber-constructed houses, the long-term influence of weather and environment, the aging and decay of timber components, as well as the alarming erosion by termites are all common views about timber architecture.

\subsection{High comprehensive construction cost}

At present, China's timber construction market is still in the early stage of development; not only the market acceptance is low with limited application, but the development planning of each timber construction enterprise is also different with uneven quality of engineering timber products in the market. At present, most timber materials in China are imported from abroad, even if only some materials or components are processed abroad, the construction cost of timber houses excluding land costs would reach 4,000-6,000 yuan per square meter ${ }^{[16]}$. In addition, most modern timber structure architectures are concentrated in tourist spots or towns and other areas, in which the transportation and labor costs are relatively high; meanwhile, the overall maintenance cost and other costs of completed timber structures ensue a higher comprehensive cost than that of other structural forms. 


\subsection{Shortage of professionals}

The lack of professional personnel training also indirectly limits the development and application of modern timber architecture. Since the 1970s, the education, training, and scientific research of timber architectural technology in relevant construction engineering courses in Chinese colleges and universities have stopped. As a result, the overall technical level of modern timber architecture in China is behind that of developed countries, such as Japan and Canada. In recent years, several colleges and universities have resumed the undergraduate elective course of timber architectural technology, some of which have resumed the postgraduate training in timber structures; however, the research and education of modern timber architectural technology in China as a whole is still lacking ${ }^{[17]}$.

Another limiting factor that affects the training of modern timber architecture professionals is the classification of its specialty. At present, timber architecture belongs to a branch of timber science and engineering in colleges and universities. This leads to the emphasis on materials courses in the training system of modern timber architecture majors, while the teaching of engineering technology related courses is relatively lacking, which results in the inability of talents to directly engage in the construction of timber architecture and develop competence for on-site engineering positions.

\section{Countermeasures and suggestions}

\subsection{Perfecting relevant policies and norms}

The development of modern timber structures cannot be separated from the promotion of policies and the perfection of norms. Under the new historical background, in recent years, China has issued a number of policies and norms to promote the development of modern timber architecture and ensuring a sustainable development. In 2015, the Action Plan for Promoting the Production and Application of Green Building Materials, which was jointly issued by the Ministry of Industry and Information Technology and the Ministry of Housing and Urban-Rural Development, advocated the construction of urban timber structures and the application of timber structures in tourist resorts. In 2016, Several Opinions on Further Strengthening the Management of Urban Planning and Construction by the State Council stated that 30\% of new houses would be built in the next decade to advocate the development of modern timber architecture [16]. In 2017, the General Office of the People's Government of Linsheng Province issued the Guiding Opinions on Promoting the Development of Timber Structure Construction Industrialization. In June the same year, the Technical Standard for Prefabricated Timber Structure Architecture was implemented (GB/T51233-2016); in August 2018, the Timber Structure Design Standard (GB50005-2017) was carried out; in November 2020, the Technical Standard for On-Site Inspection of Timber Structures (JGJ/T4882020) issued by the Ministry of Housing and Urban-Rural Development was put into effect. The General Code for Timber Structure (GB55005-2021), a national compulsory engineering construction code, was issued by the Ministry of Housing and Urban-Rural Development and was scheduled to be officially implemented from January 1, 2021. The implementation of this code broke through the bottleneck of the low-rise construction of timber structure, which ensued its expansion to middle and high-rise buildings as well as long-span structures ${ }^{[18]}$. The introduction and support of the above policies have promoted and would further promote the development and technological innovation of modern timber architecture in China.

\subsection{Strengthening technology research and development as well as demonstration guidance}

It is universally acknowledged that timber architecture has defects and deficiencies in fire prevention, earthquake prevention, moth prevention, and land possession, but these problems are no longer challenging in view of continuous technological progress and innovation. At present, the technical problems of timber 
architecture in earthquake prevention, fire prevention and flame retardant, durability modification, damage detection, and others have been tackled; in addition, green, efficient technologies with improved durability, such as lateral force-resisting systems, performance fire protection designs, and "zero-hazard" timber with high temperature modifications, have been innovated ${ }^{[18]}$. The timber components of modern timber architecture have undergone flame retardant, anti-corrosion, insect-proof treatment, and other processes, thus improving the firmness and durability. At the same time, timber components that have been treated with modern technology have optimized anti-sinking stress, anti-drying, and anti-aging as well as significantly improved stability. In addition, with regard to the flammability of timber architecture, modern timber structures are treated with water-based flame retardant treatment agent, which has carbonization effect. When these timber components encounter fire, a carbonized layer would be formed on the surface, and the low conductivity of these timber components would effectively prevent the flame from spreading inwards, thus ensuring that the whole structure would not be seriously damaged due to the spread of fire for a long period ${ }^{[12]}$.

In today's construction, dominated by concrete and steel structures, in addition to some ancient timber architectures, it seems that people have ignored the existence of timber architecture; hence, modern timber architecture is even less known. Therefore, on the one hand, it is necessary to strengthen the publicity of modern timber architecture, such as actively carrying out various seminars and theme exhibitions related to modern timber architecture, sharing new technologies and achievements, as well as strengthening exchanges within the industry; on the other hand, combined with the rapid advancement of prefabricated architecture in China in recent years, the use of prefabricated timber structure plays a demonstrated and guiding role. It is necessary to design and construct distinctive modern prefabricated timber architecture, so that people can personally understand the advantages of modern timber structures.

\subsection{Moderately developing forest resources}

After years of forest cultivation, the forest area in China is increasing year by year, ranking the fifth in the world. It is certain that everyone has the responsibility to protect forest resources and prevent these resources from being wantonly destroyed. China has also formulated relevant regulations for the protection of forest resources. It has been pointed out that the regulation aims to protect natural forests, prohibit logging, and encourage the use of artificial fast-growing forests. China has been exporting a large number of multilayer glued laminated timbers and laminated veneer timbers to foreign timber markets every year. With the development and improvement of gluing technology, it is foreseeable that logs will be inevitably replaced by manpower as timber product materials in the near future, which would break people's original concept of timber. There are three main kinds of conglomerate timbers in the market: (1) glued laminated timber (GLT) is a high-quality, beautiful, and degradable engineering composite material, which is made from small-sized solid timbers arranged along the grain direction and bonded with cold-curing adhesive; as glued timber can be made into long-span curved beams, it is widely used in the construction of stadiums and large public buildings; (2) cross-laminated timber (CLT) is a new type of timber building material, and it uses kiln-dried Chinese fir (spruce or fir) finger joints; upon sorting and cutting into timber squares, they are orthogonally superimposed, glued, and formed with high-strength materials, and then prefabricated into the required material volume, whose strength can replace concrete materials; experimental research has shown that timber structures with cross-laminated timber as the main material have good seismic performance; (3) laminated veneer lumber (LVL) is a kind of veneer made of log timber by rotary cutting or planning; after drying, gluing, and other processes, it is formed by assembling billets along the grain, and then hot pressing and gluing; it has the material characteristics of good stability, high strength, high toughness, and accurate specifications; the strength and toughness of LVL are about 3 times higher than those of solid timber ${ }^{[16]}$. 
In addition, studies have shown that there is a limit for the ability of trees to absorb carbon dioxide. With the growth of trees, the ability of trees to absorb carbon dioxide becomes weaker after the timber stage. Therefore, reasonable planning and development of forestry resources, moderate deforestation of timber, timely cultivation of new saplings, and cultivation of trees at multiple varieties, levels, and ages in forest areas are the key to realizing sustainable recycling of timber resources and reducing the dependence on imported timber, thus reducing costs ${ }^{[19]}$.

\subsection{Applying digital construction operation and maintenance technology}

In recent years, through the implementation and practice of new concepts and technologies, such as building information modeling (BIM), digital twin, intelligent construction, as well as intelligent operation and maintenance in the construction industry, the application of information technology has shown positive effect in reducing the overall construction, operation, and maintenance costs of buildings. Based on the digital building lifecycle approach, digital twin is used to map virtual space to physical space. In the construction as well as the operation and maintenance of modern timber architecture, the data information platform is used to realize the integration of physical geometric model, physical numerical model, digital twin simulation, as well as the operation and maintenance model. The comprehensive cost of modern timber architecture is reduced by means of parametric design, structural analysis simulation, construction application simulation, and information facilities management.

In addition, through the data information platform and intelligent sensing equipment, the staged health inspection of modern timber architecture can be carried out, the performance value of timber structure can be analyzed by data feedback, and its hidden danger points can be predicted, thus further ensuring the safety of modern timber architecture and preventing the occurrence of multiple disasters.

\subsection{Cultivating compound professionals}

First of all, enterprises and schools should actively join hands. Enterprises can use their own resources to provide funds, technical equipment, and projects, while schools can make use of their own professional teaching teams, teaching level, and scientific research strength. The two sides ought to carry out regional school-enterprise cooperation, actively expand cross-regional cooperation forms, build a modern "apprenticeship system," as well as innovate vocational education and certification of courses related to modern timber architecture by means of online and offline hybrid teaching, so as to deliver timber structure professionals and technical talents for the construction industry.

Secondly, the interdisciplinary system of timber architecture specialty should be constructed. With the transformation and upgrading of the construction industry, the application of new materials, BIM, machine learning, intelligent construction, and others become increasingly close to the extent of merging. In order to meet the needs of talents in the industry, the combination of cross-disciplinary and multi-disciplinary is implemented to train talents with compound skills. At the same time, college teachers should also learn and practice in enterprises, understand the actual needs and new development trends of the industry, update their teaching contents, as well as clarify the personnel training objectives.

\section{Conclusion}

The development and application of modern timber architecture is of great significance to the sustainable development of the construction industry, the reduction of carbon emissions, as well as the transformation and upgrading of the industry, which is helpful for China to realize the reform of hitting "peak carbon emissions" and attaining "carbon neutrality." It is imperative to make good use of modern timber structures, take action according to one's ability in consideration of the current social development status and demand, 
assume "precision and quality" as the construction purpose, as well as create characteristic architectures with a sense of commitment, in order to maximize the social and ecological benefits of modern timber architecture.

There are several problems in the popularization and application of modern timber architecture, such as limited resources, poor public acceptance, high comprehensive construction cost, and shortage of professional talents. The applicable scope of modern timber architecture can be expanded through policy support and improvement of norms and standards; in addition, it is necessary to strengthen technology research and development as well as demonstration guidance, in order to create modern structural construction formats and related derivative industries with regional characteristics. Developing forest resources moderately is a must to realize the sustainable recycling of timber resources. Moreover, it is essential to promote the application of digital construction as well as operation and maintenance in modern timber architecture, thereby reducing the comprehensive construction cost. In order to promote a sustainable development of modern timber architecture in China, it is imperative to add modern timber architecture courses and train up talents with compound skill level to engage in related industries.

\section{Disclosure statement}

The author declares that there is no conflict of interest.

\section{References}

[1] Xinheyuan Holding Group, 2021, World Environment Day | Wooden Buildings: Writing Green Answers to "Carbon Peak" And "Carbon Neutral”. Baidu. https://baijiahao.baidu.com/s?id=17019586 $53559764881 \& w f r=$ spider \&for $=$ pc

[2] 2019, Building Carbon Emission Calculation Standard GB/T51366-2019, Construction Industry Press, Beijing.

[3] Xi Y, (eds), A Neglected Carbon Neutralization Branch-Modern Timber Structure. Changzhou Haigou Construction Technology Co., Ltd. http://www.precast.com.cn/index.php/subject_detail-id17420.html

[4] Aalto University, 2020, Research Found That Timber Buildings Can Store Carbon Dioxide. Aggregate Cat. https://www.juhecat.com/391537.html

[5] Canadian Timber Industry, 2020, Modern Timber Structure Helps Build a "Waste-free City". Green Building, 2020(6): 08-09.

[6] Xu Q, Song J, 2021, Problems and Measures of Integrated Application of Prefabricated Modern Timber Structure Architecture. Architecture and Culture, 2021(08): 204-205.

[7] 2020, Timber Structure: Poetic Dwelling in Ecotourism. Sohu. https://www.sohu.com/a/398476418_1 20406591

[8] Wu W, Zhang W, 2019, Study on the Application of Timber Structure in Forest Health Care. Forest Products Industry, 2019(12): 93-95.

[9] CCTV, 2021, Experts and Scholars Gathered in Rongcheng to Talk About Prefabricated Timber Structure Helping Rural Revitalization. NetEase Inc. https://www.163.com/dy/article/GI0APGJ20514 R9NP.html

[10] Wang S, Cao L, 2020, Application of Timber Structure in National Forest City Construction. Forest Products Industry, 2020(07): 71-73. 
[11] 2020, Timber Has Rules. Why Is the Seismic Performance of Timber Structure Generally Better?. Know Almost. https://www.zhihu.com/question/54845497/answer/1002328920

[12] Chun DM, 2019, Why Do You Want to Live in a House with Pure Timber Structure?. Know Almost. https://zhuanlan.zhihu.com/p/55185710

[13] He M, He G, Liang F, et al., 2019, Development of Chinese Timber Structure in Recent 20 Years. Architectural Structure, 2019(19): 83-90.

[14] Lan Q, Zhang H, 2020, Development and Prospect of Timber Structure Architecture in Modern China. Intelligent Building and Smart City, 2020(01): 44-47.

[15] Wang R, Chen Y, Chen C, et al., 2019, Research on the Development Strategy of Modern Timber Structure Architecture in China. Forest Products Industry, 2019(9): 1-5.

[16] 2019, Investigation on the Present Situation of Modern Timber Structure Architecture in China. Sohu. https://www.sohu.com/a/289768647_822803

[17] Yang X, 2017, Analysis of the Development Trend of Modern Timber Structure Architecture in China. Construction Science and Technology, 2017(05): 12-15.

[18] Yang F, 2021, The Implementation of General Code for Timber Structure will Break through the Bottleneck of Low-rise Construction of Timber Structure. China National Building Materials News, (002).

[19] Zhang X, Liang Z, Yang Q, et al., 2021, Study on the Application of Timber in Construction Engineering from the Perspective of Ecological Civilization. Sichuan Building Materials, 2021(09): 22-27.

Publisher's note

Bio-Byword Scientific Publishing remains neutral with regard to jurisdictional claims in published maps and institutional affiliations. 